\title{
Pibrozelesin Hydrobromide
}

National Cancer Institute

\section{Source}

National Cancer Institute. Pibrozelesin Hydrobromide. NCI Thesaurus. Code C73816.

The hydrobromide salt form of pibrozelesin, a semisynthetic water-soluble derivative of the antineoplastic antibiotic duocarmycin B2, with antineoplastic activity. Activated by carboxyl esterase, pibrozelesin alkylates DNA by binding to adenine-thymine (A-T)-rich sequences in the minor groove of DNA, thereby inhibiting DNA replication and inducing apoptosis. 